\title{
A cost effective solution to manage rail cargo fleets: the final assessment of the F-MAN project
}

\author{
G. Cosulich ${ }^{1}$, A. Derito ${ }^{1}$, M. Giannettoni ${ }^{2} \&$ S. Savio $^{2}$ \\ ${ }^{1}$ Sciro S.p.A., Genoa, Italy \\ ${ }^{2}$ Department of Electrical Engineering, University of Genoa, Italy
}

\begin{abstract}
The objectives of the EU project Rail Car Asset Management (hereinafter referred to with its short name, F-MAN) were to investigate the feasibility, the potential impacts and benefits of a new approach toward the management of a freight railcars fleet, aiming at improving the competitiveness of Railway Cargo Operators in the context of freight transport. To reach its objectives, the F-MAN Consortium has identified the requirements, designed the architecture, specified and developed the components (on-board and ground fixed) of an IT-based system enabling enhanced fleet management of freight railcars and introducing asset management in the process of the international transport chain. In the paper the authors show the quantitative results of the final assessment of the project, describing also the characteristics of the simulation tool to this aim developed. Keywords: railway, cargo fleet management, IT-based system, simulation.
\end{abstract}

\section{Introduction}

The F-MAN project started in October 2001 from a consortium bringing together the experience, expertise, know-how and knowledge of an heterogeneous set of partners including Railway Cargo Operators (RCOs), developers of Transport and Logistics applications, Information \& Communication Technologies experts and Research Institutions [1,2]. The project was co-funded by the European Community under the Information Society Technologies (IST) Programme and provided its final results in September 2004.

The F-MAN system is made of three main modules, namely the Tracking System Module (TSM), the Data Processing Module (DPM) and the Asset Management Module (AMM). The TSM is constituted by On-Board Terminals 
(OBTs), to be installed on each wagon of the managed fleet, and a Ground Station (GS). The On-Board Terminals collect data on wagons position and status by means of GPS receivers and on board sensors, and transmit such data to the GS by means of GSM terminals. Communication is SMS based and event oriented in order to comply with the energy consumption constraints deriving from the maintenance free, long life battery providing the power source.

The GS, which is responsible for OBTs originated/terminated data buffering, pre-processing, conversion and distribution, is connected to the DPM through a secure Internet connection. The DPM is the software application responsible to maintain data relevant to the fleet composition (F-MAN Pool), past, actual and forecasted geographical distribution (Tracking and Tracing and Expected Time of Arrival - ETA), maintenance status (technical availability), and to manage the event messages communication procedures toward the OBTs. Orders processing, wagons selection and booking, trips organisation and logging of data for asset management purposes are performed through the AMM. The AMM and the DPM share a common database and are accessible through a Web Application Server. Any involved user connects himself to the system through the Internet by means of a simple browser. The F-MAN system provides its users with the so called F-MAN tools, i.e. a set of user friendly interfaces to the system (automatic multi language support is implemented) assisting and driving the user throughout any task he's responsible for. The F-MAN tools were developed and integrated into a prototype, whose functions were successfully tested during real operating conditions by monitoring 50 wagons (suitably equipped) from the French, Portuguese and Slovenian railways [3]. Anyway, given the reduced number of tested railcars, a simulation tool was developed within an evaluation Work package, whose primary task was the assessment of the project results effectiveness. In particular, simulations aimed at evaluating the effectiveness of the algorithms and procedures implemented by the F-MAN application when operating on a significant pool of wagons (e.g. thousands of wagons): the scope of such simulations was to gather data enabling a fair comparison between the performances (such as fleet productivity) obtainable from a fleet operated according to the F-MAN approach and those relevant to the nowadays management practice.

\section{Simulator characteristics}

The simulator was designed and developed to run on the Microsoft Access database engine (Microsoft ${ }^{\circledR}$ Access 2000). It was not intended to emulate the traffic related to wagon movements (there is no representation of railway network layout, capacity, etc.) but only the fleet management approach toward orders fulfilment. To explain such concept with a few words:

$>$ when an order is processed, the engine queries the database for suitable wagons (available in the origin station on departure date), according to predefined criteria;

$>$ if all the wagons have been found, the order is satisfied and wagons will become available again in the destination station at the arrival date. 
The following assumptions and requirements have been considered to design and develop the simulation software:

$>$ during the simulation, the total number of wagons in the model is fixed;

$>$ each wagon is identified by a unique wagon identifier and by a wagon owner identifier;

$>$ each station is defined with an initial number of available wagons;

$>$ each station-to-station path is characterised by a mileage;

$>$ trip time for each path is calculated considering an average speed, which may be different for international and domestic trips;

$>$ wagons unavailability time $\left(\mathrm{T}_{\mathrm{wu}}\right)$ can be set as a parameter (e.g., to take into account wagons loading and unloading, or other marshalling operations), so that a wagon can be used for a given task only if the wagon is available for the task at least $\mathrm{T}_{\mathrm{wu}}$ hours earlier;

$>$ the fleet manager is aware of new orders from any origin to any final destination (inside or outside the origin Country) at departure time $\mathrm{D}_{0}-\tau_{\mathrm{b}}$, being $\tau_{\mathrm{b}}$ a random variable representing the booking time;

trip times are always the scheduled ones.

Orders lists are generated off-line by Excel ${ }^{\circledR}$ macros and then exported to feed the simulator database; any order list is generated for a given number of days, starting from a predefined date. For each origin-destination combination, the orders are generated on the basis of the following criteria:

$>$ a stochastic distribution of wagons per order, from each origin to each destination, is defined to generate the order lists;

$>$ number of orders/day (e.g. 2 if the relevant transport is operated twice a day);

$>$ mean value and standard deviation of the distribution used to extract the number of wagons requested by a single order.

Once lists have been generated, orders are processed by the simulator according to the following criteria:

$>$ orders are processed according to order date;

$>$ orders for the nearest departure date are processed first;

$>$ only orders which can be satisfied $100 \%$ are processed;

$>$ each day wagons are booked based on wagons availability and cost of availability;

$>$ for international trips, wagons belonging to the destination Country are selected first;

$>$ re-processing of orders is not allowed.

As far as management models are concerned, it is worth noting that the traditional management model implemented for the simulations takes into account the RIV regime as a reference. Although the EUROP regime would be more similar to the F-MAN pool concept, the Consortium has preferred to carry out the comparison with the RIV regime in order to have the feeling of the potential impacts of the application with respect to the current management policies, being the EUROP regime abandoned.

At last, performance indicators addressed by simulations are listed below (to estimate indicators, the "fleet" is always considered as the whole set of wagons): 
Performance ID 1: fleet productivity computed on a time basis [revenue time/(revenue time + empty time)];

Performance ID 2: fleet productivity computed on a mileage basis [loaded mileage/(loaded mileage + empty mileage)];

Performance ID 3: rate of satisfied wagon requests [delivered wagons/requested wagons];

Performance ID 4: rate of satisfied orders [fulfilled orders/number of orders].

\section{Case studies}

The authors analysed many different scenarios related to the management of a cargo traffic flow among three areas (Countries), each characterised by four departure/arrival stations.

The first differentiation of simulation scenarios was made by varying the composition of the orders lists to be processed by the simulator. In particular, the following families of orders lists were utilised:

$>$ National 120 days: orders list for 120 days, with approximately 72 orders/day (about 8600 orders and 150000 wagons request), with $75 \%$ national trips and $25 \%$ international trips;

$>$ International 120 days: roughly the same number of orders and wagons request as above, but with $25 \%$ national trips and $75 \%$ international trips;

$>$ International 240 days: the same composition as International 120 days, but distributed on 240 days, thus with approximately 36 orders/day.

Further major elements determining the simulation scenario were the wagons fleet size and the distribution of wagons among stations at the beginning of the simulation.

As far as the initial wagons distribution is concerned, test simulations were performed in order to verify that the impact of uneven distributions is limited in time from the beginning of the simulation: this is compliant with the fact that both the Traditional and the F-MAN management approaches have the capability to move wagons where they are needed. However, in order to avoid biasing of simulation results utilised for evaluation purposes, wagons were always equally distributed among stations.

The following fleet sizes were considered in the simulations:

$>$ Large fleet: 4800 wagons equally distributed among the stations (400 wagons/station);

$>$ Reduced fleet (F-MAN only): 3600 wagons (300 wagons/station);

$>$ Small fleet: 2400 wagons equally distributed among the stations (200 wagons/station).

The authors set the average speed for domestic and international trips respectively equal to $30 \mathrm{~km} / \mathrm{h}$ and $18 \mathrm{~km} / \mathrm{h}$, while a value ranging from 4 to 10 days was used for the "send-back" time of RIV wagons (a wagon outside its proprietor's Country must be repatriated within this time, regardless it can be sent back loaded or not). 
As far as the wagons unavailability time $\left(\mathrm{T}_{\mathrm{wu}}\right)$ is concerned, such parameter was set equal to $0 \mathrm{~h}$ in all simulations except for those developed to estimate the impact of the accuracy of ETA information on the system performances.

\section{Simulation results}

In this chapter the authors present some of the most interesting results of the simulations. A summary of the results obtained from the simulations relevant to heavy traffic (National - International 120 days) and undersized fleet (2400 wagons) scenarios is presented in the following Table 1.

Table 1: Summary of the simulation results (heavy traffic - undersized fleet).

\begin{tabular}{|l|c|c|c|c|c|c|}
\cline { 2 - 7 } \multicolumn{1}{c|}{} & \multicolumn{3}{c|}{ National 120 days - 2400 wagons } & \multicolumn{3}{c|}{ International 120 days - 2400 } \\
\cline { 2 - 7 } \multicolumn{1}{c|}{} & Traditional & F-MAN & $\Delta \%$ & Traditional & F-MAN & $\Delta \%$ \\
\hline Performance ID 1 & 0.77 & 0.95 & $+24 \%$ & 0.84 & 0.98 & $+16 \%$ \\
\hline Performance ID 2 & 0.74 & 0.94 & $+28 \%$ & 0.79 & 0.97 & $+23 \%$ \\
\hline Performance ID 3 & 0.72 & 0.96 & $+34 \%$ & 0.54 & 0.75 & $+38 \%$ \\
\hline Performance ID 4 & 0.74 & 0.97 & $+31 \%$ & 0.58 & 0.80 & $+37 \%$ \\
\hline $\begin{array}{l}\text { Loaded mileage } \\
{[\text { Mkm] }}\end{array}$ & 51.8 & 70.9 & $+37 \%$ & 57.6 & 79.6 & $+38 \%$ \\
\hline $\begin{array}{l}\text { Empty mileage } \\
{[\text { Mkm] }}\end{array}$ & 18.3 & 4.4 & $-76 \%$ & 15.7 & 2.7 & $-83 \%$ \\
\hline $\begin{array}{l}\text { Wagons cycle } \\
\text { time [h] ([days]) }\end{array}$ & $\begin{array}{c}66.7 \\
(2.8)\end{array}$ & $\begin{array}{c}50.0 \\
(2.1)\end{array}$ & $-25 \%$ & $\begin{array}{c}88.4 \\
(3.7)\end{array}$ & $\begin{array}{c}64.3 \\
(2.7)\end{array}$ & $-27 \%$ \\
\hline
\end{tabular}

Such table shows, for the Traditional management approach and the F-MAN pool management approach, the following data, calculated as mean values over 5 replications for each orders list composition:

performance indicators, as defined in the previous Section 2;

$>$ loaded mileage of the fleet (sum of all the $\mathrm{km}$ relevant to movements of loaded wagons);

$>$ empty mileage of the fleet (sum of all the $\mathrm{km}$ relevant to movements of empty wagons);

> fleet wagons cycle time $\left(\mathrm{T}_{\mathrm{wc}}\right)$, considered as the mean time between two successive missions of a wagon and computed as it follows:

$$
\mathrm{T}_{\mathrm{wc}}=\frac{\mathrm{N}_{\mathrm{w}} \mathrm{T}_{\mathrm{s}}}{\sum_{\mathrm{i}=1}^{\mathrm{N}_{\mathrm{so}}} \mathrm{N}_{\mathrm{wi}}}
$$

where:

$\mathrm{N}_{\mathrm{w}}=$ total number of wagons

$\mathrm{T}_{\mathrm{s}}=$ total simulation time 
$\mathrm{N}_{\mathrm{so}}=$ number of satisfied orders

$\mathrm{N}_{\mathrm{wi}}=$ number of wagons for the $i$-th satisfied order

Difference (in percentage) between the F-MAN values and the Traditional (i.e., reference case) values are reported as well.

It is straightforward noting that the F-MAN pool management approach always achieves better performances than the Traditional management approach:

$>$ F-MAN enhances the exploitation of the fleet, as the loaded mileage (payload) increases;

$>$ F-MAN improves the productivity of the fleet, as the increase of the loaded mileage is achieved with a striking reduction of the empty mileage.

Although the F-MAN approach had been conceived to improve cargo fleet performances for international traffic flows, it is worth noting that the benefits are remarkable also in scenarios characterised by a majority of domestic traffic (National). In fact, despite international traffic weight is just around $25 \%$ of the total traffic in the National orders list composition, the impact of the F-MAN approach is estimated as about a $30 \%$ increase in the capability of satisfying orders requests, contemporaneously reducing the movements of empty wagons to about $25 \%$ of the empty movements needed in the Traditional approach. This is a result that goes over and above the most optimistic expectations.

Simulation results show that, when the traffic scenario is shifted from National to International, performance indicators relevant to loaded time and mileage increase, while the empty mileage and the indicators relevant to the fulfilment of orders request decrease, for both management approaches.

Such behaviour is a direct consequence of the characteristics of the International traffic scenario analysed and of the fleet size (undersized). In particular, moving from the National orders list to the International one, the frequency of orders request for transport from a given station to stations of other Countries significantly increases, with an increase of both the mean trip distance and the mean time to accomplish an order.

Moreover, the send back time (RIV regime) for those simulations was set to 10 days, a period during which each station has plenty of orders to be fulfilled (most of them to foreign Countries for the International orders list). Under those conditions, each Country has many occasions to load and send a foreign wagon to the belonging Country, without any need for sending it empty just to comply with the send back time.

All the considerations mentioned above clearly testify the reasons why the benefits deriving from the adoption of the F-MAN approach in the case of the International scenario, although definitely huge, are analogous to the ones related to the National scenario, as the operating conditions are in the latter case favourable on the side of the Traditional management.

The second set of results presented by the authors deals with the simulations carried out in order to estimate the impact of ETA accuracy on the performances of the F-MAN Pool management approach as implemented by the simulator model. The estimate has been carried out by means of a sensitivity analysis on the $\mathrm{T}_{\mathrm{wu}}$ parameter, i.e. the value of the wagons unavailability time. As mentioned 
before, this is the time during which a wagon, following the completion of its mission, is not yet available. Such parameter, originally introduced to take into account the loading/unloading time, has been used to take into account the ETA accuracy instead. Despite representing a rough - but working - method expected to penalize the performance more than in the real implementation of the system (the relevant unavailability time is applied after any completed mission), this allows to evaluate what the performance would be (in the worst case) when the F-MAN AMM considers a time equal to $T_{w u}$ as the accuracy of the ETA information. Results summarised in Table 2 for simulation scenarios characterised by heavy traffic and sufficient fleet (to fulfil all the orders when $\mathrm{T}_{\mathrm{wu}}$ is set to 0) show that when the accuracy of ETA decreases (simulated through an increase of $\mathrm{T}_{\mathrm{wu}}$ ), the performances decrease as well, since the number of rejected orders and undelivered wagons increase, while the loaded mileage decreases. It is worth noting that the slight increase of performance indicators ID 1 and ID 2 is only due to the lower number of running wagons as a consequence of the lower number of satisfied orders.

Table 2: $\quad$ Impact of $\mathrm{T}_{\text {wu }}$ parameter (heavy traffic - sufficient fleet).

\begin{tabular}{|c|c|c|c|c|}
\hline \multirow[b]{2}{*}{$\mathbf{T}_{\mathrm{wu}}[\mathbf{h}]$} & \multicolumn{4}{|c|}{ International 120 days - 3600 wagons } \\
\hline & $\mathbf{0}$ & 6 & 10 & 18 \\
\hline Performance ID 1 & 0.965 & 0.966 & 0.969 & 0.973 \\
\hline Performance ID 2 & 0.958 & 0.958 & 0.960 & 0.962 \\
\hline Performance ID 3 & 1 & 0.986 & 0.967 & 0.894 \\
\hline Performance ID 4 & 1 & 0.994 & 0.981 & 0.925 \\
\hline $\begin{array}{ll}\text { Loaded } & \text { mileage } \\
{[\mathrm{Mkm}]}\end{array}$ & 107.1 & 106.4 & 104.5 & 96.3 \\
\hline $\begin{array}{l}\text { Empty mileage } \\
{[\mathrm{Mkm}]}\end{array}$ & 4.6 & 4.7 & 4.3 & 3.8 \\
\hline $\begin{array}{l}\text { Wagons cycle time } \\
{[\mathrm{h}]([\text { days }])}\end{array}$ & $\begin{array}{c}71.2 \\
(3) \\
\end{array}$ & $\begin{array}{l}71.7 \\
(3)\end{array}$ & $\begin{array}{c}73.1 \\
(3) \\
\end{array}$ & $\begin{array}{l}79.1 \\
(3.3) \\
\end{array}$ \\
\hline Rejected orders & 0 & 41 & 139 & 547 \\
\hline Undelivered wagons & 0 & 865 & 3129 & 12118 \\
\hline
\end{tabular}

In the last section of this chapter the authors present the results of the analysis carried out to evaluate the potential impact of the F-MAN Pool management approach on the productivity of a fleet of wagons, taking into account economical issues as well. It is worth noting that the indicators previously utilised to score the performance of the management approaches are not sufficient to this aim; thus another indicator linking together those already mentioned with the costs of owning and operating the fleets is introduced.

The indicator utilized by the authors is the daily wagon productivity $\left(\mathrm{P}_{\mathrm{wd}}\right)$, defined as follows, respectively for the Traditional and the F-MAN wagon (subscript -T and -F applies for Traditional and F-MAN fleet respectively):

$$
\mathrm{P}_{\mathrm{wd}-\mathrm{T}}=\left[\mathrm{R}_{\mathrm{lt}} \mathrm{N}_{\mathrm{kml}-\mathrm{T}}-\left(\mathrm{C}_{\mathrm{wd}} \mathrm{N}_{\mathrm{w}-\mathrm{T}} \mathrm{T}_{\mathrm{D}}+\mathrm{C}_{\mathrm{et}} \mathrm{N}_{\mathrm{kme}-\mathrm{T}}\right)\right] /\left(\mathrm{N}_{\mathrm{w}-\mathrm{T}} \mathrm{T}_{\mathrm{D}}\right)
$$




$$
P_{w d-F}=\left[R_{l t} N_{k m l-F}-\left(K_{F} C_{w d} N_{w-F} T_{D}+C_{e t} N_{k m e-F}\right)\right] /\left(N_{w-F} T_{D}\right)
$$

where:

$\mathrm{N}_{\mathrm{w}}$ = total number of wagons in the fleet

$\mathrm{N}_{\mathrm{kml}}=$ total loaded mileage of the fleet $[\mathrm{km}]$

$\mathrm{N}_{\mathrm{kme}}=$ total empty mileage of the fleet $[\mathrm{km}]$

$\mathrm{T}_{\mathrm{D}}=$ observed time period [days]

$\mathrm{C}_{\mathrm{wd}}=$ daily cost of owning a wagon (used or not) [€/day]

$\mathrm{C}_{\mathrm{et}}=$ cost per $\mathrm{km}$ of moving an empty wagon $[€ / \mathrm{km}]$

$\mathrm{R}_{\mathrm{lt}}=$ net revenue per $\mathrm{km}$ for a loaded wagon $[€ / \mathrm{km}]$

$\mathrm{K}_{\mathrm{F}}=\mathrm{F}-\mathrm{MAN}$ equipment factor $(>1$, takes into account the daily cost of OBT and communication)

Being the values of $\mathrm{C}_{\mathrm{wd}}, \mathrm{C}_{\mathrm{et}}$ and $\mathrm{R}_{\mathrm{lt}}$, in the real context, highly variable from RCO to RCO and from wagon type to wagon type, the analysis was carried out estimating the values of the daily wagon productivity in per units of the daily cost of a wagon $\left(\mathrm{C}_{\mathrm{wd}}\right)$, defined as:

$$
\begin{gathered}
\mathrm{p}_{\mathrm{wd}-\mathrm{T}}=\left[\mathrm{C}_{1} \mathrm{~N}_{\mathrm{kml}-\mathrm{T}}-\left(\mathrm{N}_{\mathrm{w}-\mathrm{T}} \mathrm{T}_{\mathrm{D}}+\mathrm{C}_{2} \mathrm{~N}_{\mathrm{kme}-\mathrm{T}}\right)\right] /\left(\mathrm{N}_{\mathrm{w}-\mathrm{T}} \mathrm{T}_{\mathrm{D}}\right) \\
\mathrm{p}_{\mathrm{wd}-\mathrm{F}}=\left[\mathrm{C}_{1} \mathrm{~N}_{\mathrm{kml}-\mathrm{F}}-\left(\mathrm{K}_{\mathrm{F}} \mathrm{N}_{\mathrm{w}-\mathrm{F}} \mathrm{T}_{\mathrm{D}}+\mathrm{C}_{2} \mathrm{~N}_{\mathrm{kme}-\mathrm{F}}\right)\right] /\left(\mathrm{N}_{\mathrm{w}-\mathrm{F}} \mathrm{T}_{\mathrm{D}}\right)
\end{gathered}
$$

where:

$\mathrm{C}_{1}=\mathrm{R}_{\mathrm{lt}} / \mathrm{C}_{\mathrm{wd}}$

$\mathrm{C}_{2}=\mathrm{C}_{\mathrm{et}} / \mathrm{C}_{\mathrm{wd}}$

To carry out the analysis $\mathrm{K}_{\mathrm{F}}$ was set to 1.1 , considering a daily wagon cost of about $€ 15$ (a mean value derived from the information provided by users within the Consortium) and the following data related to F-MAN equipment:

$>$ OBT provision and installation equal to about $€ 2500$;

$>$ OBT life (maintenance free) equal to 5 years;

$>$ mean daily communication cost per wagon equal to about $€ 0.12$.

In Figures 1 and 2 the authors present the results related to the data collected during the simulation of the heavy (International 120 days) traffic - sufficient fleet scenario (send back time for the RIV regime set to 4 days).

It is worth noting that, due to the different performances of the F-MAN management with respect to the Traditional one, the need for a suitable number of wagons able to satisfy almost all the orders resulted in an F-MAN fleet size smaller than the Traditional one (3600 and 4800 wagons respectively). In particular, Figure 1 shows the per cent daily wagon productivity increase of F-MAN with respect to the Traditional management as a function of $\mathrm{C}_{1}$ and $\mathrm{C}_{2}$, in the ranges $[0.06,0.1]$ and $[0.02,0.04]$ respectively. Figure 2 presents three cross sections of the previous Figure 1, i.e. the per cent daily wagon productivity increase of F-MAN with respect to the Traditional management as a function of $\mathrm{C}_{1}$ for three fixed values of $\mathrm{C}_{2}$. 


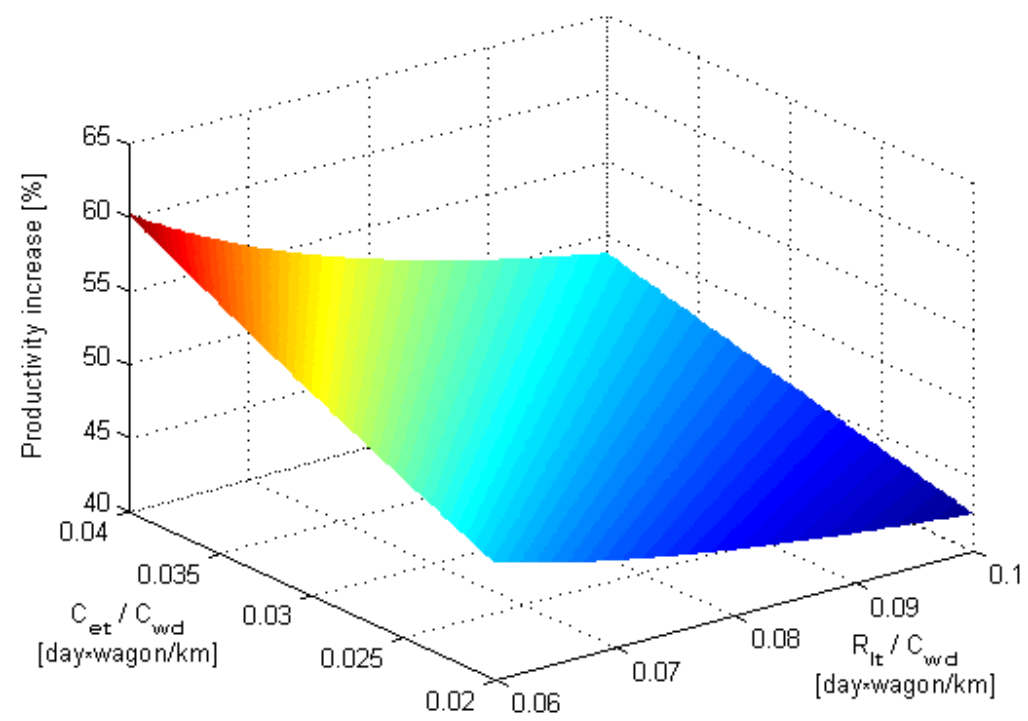

Figure 1: Daily wagon productivity increase with F-MAN.

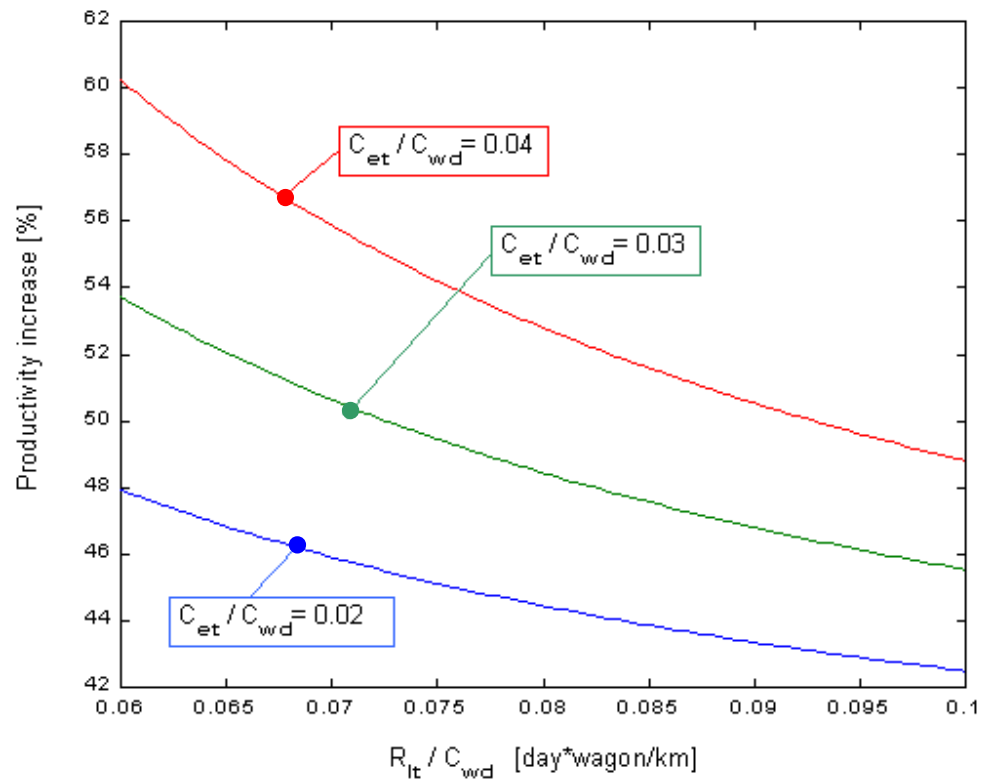

Figure 2: Daily wagon productivity increase with F-MAN (fixed $\mathrm{C}_{\mathrm{et}} / \mathrm{C}_{\mathrm{wd}}$ ).

The reported results clearly show that the F-MAN Pool management approach is estimated to significantly improve the productivity of the fleet.

Depending on fleet specific costs, the percentage increase of the daily wagon productivity may range from approximately $40 \%$ up to $60 \%$ and more. Although this is quite a wide spread, such result is definitely a very positive one. 
Of course the actual costs borne by the RCO to implement and utilise the F-MAN system will largely depend on commercial agreements with OBT suppliers and mobile communication providers, so that the actual value of $\mathrm{K}_{\mathrm{F}}$ for a specific wagon type may differ from 1.1.

For such reasons, the authors carried out a sensitivity analysis in order to evaluate the impact of an increase of the parameter $\mathrm{K}_{\mathrm{F}}$ on the effectiveness of the F-MAN solution. Such final analysis demonstrated that the impact of the costs of the F-MAN system on fleet productivity is very limited.

To give an example, in the relaxed (International 240 days) traffic - oversized fleet scenario (3600 and 4800 wagons for the F-MAN fleet and the Traditional one respectively), which resulted the worst case as far as fleet productivity is concerned, even if $\mathrm{K}_{\mathrm{F}}$ equals 2 (i.e. the daily cost per wagon of the overall F-MAN system equals the daily cost of owning a wagon) the productivity increase would still be around $45 \%$ (send back time for the RIV regime set to 4 days).

\section{Conclusions}

The main results of the final assessment of the EU project F-MAN have been presented by the authors in this paper. F-MAN developed and tested a web based IT application providing a set of tools enabling a new approach to fleet management in railway freight transports. The F-MAN pool regime implementation would allow Railway Cargo Operators to gain 2 digits productivity increase on both national and international transports. Comparisons made with other management regimes, such as RIV, show the productivity increase can be estimated between $40 \%$ and $60 \%$, or even more.

Again, it has to be reminded that such results have been obtained through simulations implementing simplified models of the management processes, but a qualitative analysis of the results allows to conclude that the development of the F-MAN system as an industrial quality product, together with the adoption of the F-MAN Pool approach, show concrete potentialities to represent a very good deal for both developers and users.

\section{References}

[1] Bozzo, R., Derito, A., Kuhla, E., Nurchi, R. \& Recagno, V., A vision of future freight rail fleet management, Proc. of the World Congress on Railway Research WCRR 2001, Köln, Germany, 25-29 November 2001.

[2] Ballis, A., Guigon, M. \& Kuhla, E., F-MAN will boost wagon productivity in Europe, Railway International Gazette, November 2003 issue, pp. 701-703.

[3] Giannettoni, M. \& Savio, S., Fleet management in railway freight transport: the EU project F-MAN, Proc. of the Int. Conf. COMPRAIL 2004, Dresden, Germany, 17-19 May 2004. 